\title{
The Management of Thyroid Nodules
}

\author{
A Retrospective Analysis of Health Insurance Data
}

Romy Wienhold, Markus Scholz, Jürgen-Bernhard Adler, Christian Günster, Ralf Paschke

\section{SUMMARY}

Background: In Germany, about 59000 thyroid operations are performed each year for uni- or multinodular goiter, most of them for diagnostic purposes. The rate of detection of thyroid cancer in such operations is relatively low, at 1:15. Evidence suggests that the preoperative tests recommended in guidelines for estimating the risk of cancer are not being performed as often as they should. In the present study, we determined the measures that were actually taken to diagnose and treat thyroid nodules and compared the findings with the guideline recommendations.

Method: We retrospectively analyzed data from a single, large statutory healthinsurance carrier in Germany (AOK), determining the diagnostic and therapeutic measures that were reimbursed for 25600 patients in whom a uni- or multinodular goiter was newly diagnosed in the second quarter of 2006 (none of these patients had carried such a diagnosis 1 year previously). We recorded the diagnostic measures performed in the preceding 9 months and all other tests and treatments, including surgery and radioactive iodine treatment, in the 2 years thereafter.

Results: Among patients who underwent surgery for uninodular goiter, the preoperative diagnostic studies included ultrasonography (in 100\% of patients), scintigraphy (94\%), measurement of thyroid-stimulating hormone (95\%), measurement of calcitonin (9\%), and fine-needle aspiration cytology (FNAC) (21\%). An ultrasonographic examination was billed for only $28 \%$ of patients with uninodular goiter in the two years after the diagnosis was made. $13 \%$ of patients with uninodular goiter who were not operated on were given L-thyroxine, even though this is against guideline recommendations.

Conclusion: Inadequate preoperative risk stratification of thyroid nodules may explain the large number of thyroid operations that are performed for diagnostic purposes, resulting in a low percentage of malignancies detected. Preoperative FNAC and calcitonin measurement should be used in the diagnostic evaluation of thyroid nodules far more often than this is now done. As a rule, follow-up ultrasonography should be performed for all thyroid nodules that are not operated on. Patients with non-operated thyroid nodules should not be given thyroxine. A limitation of this study is that diagnostic measures were only recorded if they were performed in the 9 months before surgery, with earlier diagnostic measures (if any) being missed.

\section{Cite this as:}

Wienhold R, Scholz M, Adler JB, Günster C, Paschke R:

The management of thyroid nodules-a retrospective analysis of health insurance data. Dtsch Arztebl Int 2013; 110(49): 827-34.

DOI: 10.3238/arztebl.2013.0827

Division of Nephrology_-Department of Internal Medicine, Neurology and Dermatology, Universitätsmedizin Leipzig: Wienhold, Prof Dr. med. Paschke

Wissenschaftliches Institut der AOK (WId0, AOK's Scientific Institute): Adler, Günster

Institute for Medical Informatics, Statistics and Epidemiology (IMISE), University of Leipzig: Prof. Dr. rer. nat. Scholz onography reveals thyroid nodules in around $20 \%$ of 20 - to 79 -year-old persons resident in Germany (1). Any European found to have a thyroid nodule should be examined to exclude thyroid autonomy and thyroid carcinoma. The annual incidence (age-standardized rate of new cases, European standard) of thyroid cancer in Germany is 7.5 per 100000 for women and 3.2 per 100000 for men, with standardized mortality of 0.5 in each case (2). In regions with (previous) iodine deficiency, functional thyroid autonomy is the most frequent cause of hyperthyroidism $(10 \%$ and $5 \%$ of thyroid nodules respectively) $(3,4)$.

The frequent occurrence of thyroid nodules necessitates rational, risk-adapted differential diagnostic strategies and methods to identify the small proportion of nodules with an elevated risk of cancer or with thyroid autonomy. Two sets of evidence-based guidelines $(5,6)$ and two consensus statements $(7,8)$ describe the diagnosis and management of thyroid nodules by means of such strategies.

Of these publications, only the revised AACE/AME/ ETA guidelines (5) are devoted exclusively to the differential diagnosis and treatment of benign thyroid nodules. They take account of the typical epidemiological characteristics of the previously iodine-deficient areas of Europe and the resulting diagnostic features.

Despite the high level of agreement among the current sets of guidelines, considerable gaps in the evidence remain (9). The new guidelines are distinguished from previous recommendations by:

- Increasing precision pertaining to the integration of the various diagnostic tools

- Growing importance of sensitive ultrasound criteria of malignancy for selection of thyroid nodules for treatment by fine-needle aspiration cytology (FNAC).

At ca. 80000 thyroid operations per year (59 000 of them for nodular goiter) (11), Germany has a high rate of thyroid surgery compared, for example, with the USA (75 000 operations annually) (10). However, the rate of malignancy in "diagnostic thyroid surgery" for a thyroid nodule is lower in Germany than in other European countries (ratio of malignant to benign goiter: Germany 1:15 [12], Italy $1: 7$ [13], England and Scandinavia $1: 5[14,15])$.

With regard to the diagnosis and treatment of thyroid nodules, case-based surveys in Germany and other European countries have revealed clear evidence of discrepancies between guideline recommendations and actual daily practice (16-19). 
FIGURE 1

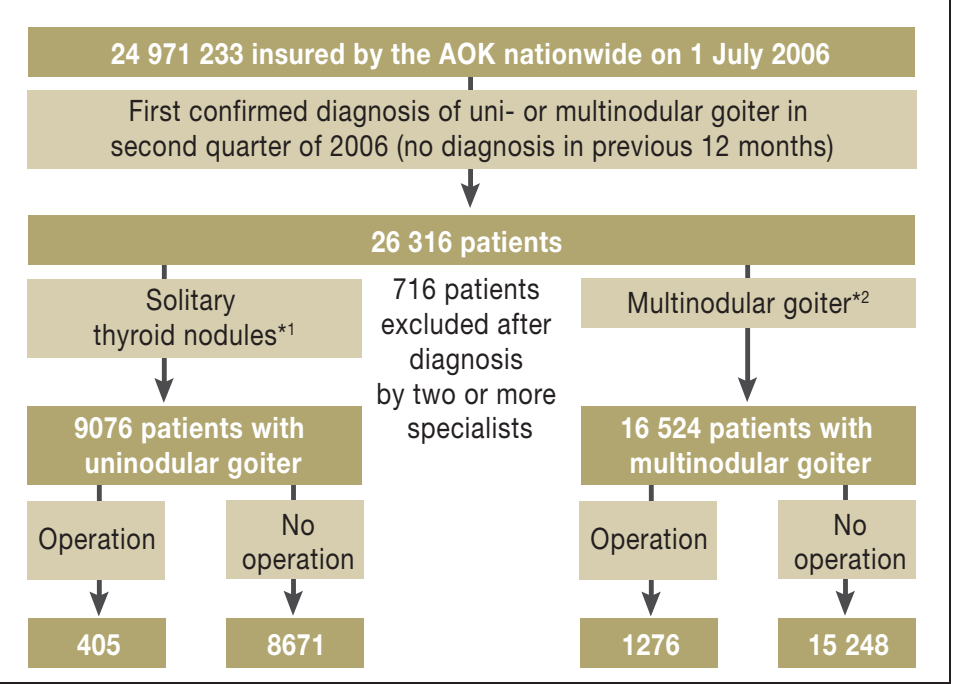

Patient selection

${ }^{* 1}$ ICD classification (International Statistical Classification of Diseases and Related Health Problems) E041; *2 ICD classification E042 or E011

For this reason, we analyzed the health insurance data of $30.4 \%$ of the German population to identify all patients with a first diagnosis of uni- or multinodular goiter and investigated the diagnostic and therapeutic procedures employed in this group. This was the first analysis to cover such a high proportion of the population. As in studies of other diseases (20-23), the aim was to establish how thyroid nodules are currently managed in practice and compare this with the recommendations in the guidelines.

\section{Method}

The analysis was based on anonymized, routinely collected data from a large statutory health insurance provider, the Allgemeine Ortskrankenkasse (AOK). The nature of these data enabled assignment of various hospital stays and physician visits to one and the same patient without permitting re-identification of the person concerned. Data from the years 2005 to 2008 were used.

On the reference date of 1 July 2006, the AOK provided health insurance for 24971233 persons. Analysis of care provision and prescription data identified 25600 patients insured by the AOK who were not treated as hospital inpatients and in whom physicians of one single specialty made a first, confirmed diagnosis of uni- or multinodular goiter in the second quarter of 2006 (with no diagnosis during the previous 12 months).

Of these 25600 patients, 9076 were assigned to ICD-10 code E04.1: "Nontoxic single thyroid nodule." We refer to these thyroid glands as "uninodular."

The remaining 16524 patients were assigned to ICD code E04.2: "nontoxic multinodular goiter (cystic goiter NOS [not otherwise specified], multinodular [cystic] goiter NOS)" or E01.1: "Iodine deficiency-re- lated multinodular (endemic) goiter." We refer to these thyroid glands as "multinodular."

For both uni- and multinodular patients, we evaluated all diagnostic services billed to the AOK during the 9 months immediately preceding the second quarter of 2006 and all subsequent examinations and treatments (including surgical interventions and radioiodine therapy) billed during a period of 2 years directly following the second quarter of 2006. The patient selection procedure is depicted in Figure 1. In both the uninodular and the multinodular group, patients who underwent surgery $(405 / 1276)$ were evaluated separately from those who did not (8671/15 248).

The percentages in Tables 1-4 refer to the number of patients for whom the given examination was billed expressed as a proportion of the patients in the subgroup concerned (uninodular/multinodular, surgery/no surgery) originally diagnosed by the respective group of physicians.

The prescription data and the Anatomical Therapeutic Chemical (ATC) Classification System for 2006 were used to identify prescriptions of L-thyroxine (H03AA01) and preparations combining L-thyroxine and iodide (H03AA51) in the 2 years immediately following the second quarter of 2006.

A detailed description of the method can be found in the $e$ Box.

\section{Results}

All of the patients with surgery for uninodular goiter underwent ultrasonography, and $94 \%$ had scintigraphy. The concentration of thyroid-stimulating hormone (TSH) was determined in $95 \%$ of patients, the calcitonin level was measured in $9 \%$, and $21 \%$ had FNAC. Preoperative calcitonin screening was billed in only $7 \% / 9 \%$ of the patients with uninodular/multinodular goiter who did not have surgery (Table 2a). Preoperative FNAC was billed most frequently by nuclear medicine specialists $(42 \%)$ in patients with uninodular goiter (Table 2b).

Scintigraphy and sonography were employed similarly often, predominantly in surgically treated patients; the frequency of these examinations varied markedly among the different medical specialties (Table 2b).

Following initial scintigraphy to confirm the diagnosis, $11 \%$ of all patients underwent scintigraphy at least once more in the course of the next 2 years. Around one third of these follow-up examinations were in patients with uninodular goiter, two thirds in multinodular goiter. The distribution of repeat scintigraphies across specialties was similar in the two groups of patients (uninodular/multinodular goiter):

- Internal medicine: $5 \% / 6 \%$

- Primary care: $7 \% / 6 \%$

- Nuclear medicine: $21 \% / 21 \%$

- Surgery: $12 \% / 9 \%$

- Others: $14 \% / 13 \%$

Strikingly, scintigraphy was repeated in $20 \%$ of patients who received surgery and $8 \%$ of those who did not. The data did not permit division of the internists 
Distribution of the diagnosing physicians by specialty

\begin{tabular}{|c|c|c|c|c|c|}
\hline \multirow[b]{2}{*}{ Diagnosis } & \multirow[b]{2}{*}{ Specialty } & \multicolumn{2}{|c|}{ Surgically managed } & \multicolumn{2}{|c|}{ Nonsurgically managed } \\
\hline & & $\begin{array}{l}\text { Number of } \\
\text { patients }\end{array}$ & $\begin{array}{l}\% \text { of all patients with this } \\
\text { diagnosis }(95 \% \mathrm{Cl})\end{array}$ & $\begin{array}{l}\text { Number of } \\
\text { patients }\end{array}$ & $\begin{array}{l}\% \text { of all patients with this } \\
\text { diagnosis }(95 \% \mathrm{Cl})\end{array}$ \\
\hline \multirow{6}{*}{$\begin{array}{l}\text { Uninodular } \\
\text { goiter }\end{array}$} & Internal medicine & 159 & $39.3(34.5-44.2)$ & 3408 & $39.3(38.3-40.3)$ \\
\hline & Primary care & 130 & $32.1(27.6-36.9)$ & 2899 & $33.4(32.4-34.4)$ \\
\hline & Nuclear medicine & 40 & $9.9(7.2-13.2)$ & 1014 & $11.7(11.0-12.4)$ \\
\hline & Surgery & 15 & $3.7(2.1-6.0)$ & 59 & $0.7(0.5-0.9)$ \\
\hline & Others & 61 & $15.1(11.7-18.9)$ & 1291 & $14.9(14.1-15.7)$ \\
\hline & Total & 405 & 100.0 & 8671 & 100.0 \\
\hline \multirow{6}{*}{$\begin{array}{l}\text { Multinodular } \\
\text { goiter }\end{array}$} & Internal medicine & 413 & $32.4(29.8-35.0)$ & 5878 & $38.5(37.8-39.3)$ \\
\hline & Primary care & 368 & $28.8(26.4-31.4)$ & 4321 & $28.3(27.6-29.1)$ \\
\hline & Nuclear medicine & 254 & $19.9(17.7-22.2)$ & 2712 & $17.8(17.2-18.4)$ \\
\hline & Surgery & 45 & $3.5(2.6-4.7)$ & 112 & $0.7(0.6-0.9)$ \\
\hline & Others & 196 & $15.4(13.4-17.5)$ & 2225 & $14.6(14.0-15.2)$ \\
\hline & Total & 1276 & 100.0 & 15248 & 100.0 \\
\hline
\end{tabular}

$95 \% \mathrm{Cl}, 95 \%$ confidence interval

into subspecialties, e.g., endocrinology. Tables $3 a$ and $3 b$ show the follow-up examinations billed within 2 years after diagnosis (overall and by specialty).

By specialty, the proportions of patients with uninodular goiter whose disease was managed operatively within 2 years of diagnosis were $4 \%$ for primary care, $5 \%$ for internal medicine, $4 \%$ for nuclear medicine, and $20 \%$ for surgery (Table 4 ). Physicians in each of the specialties selected surgical management with similar frequency for uninodular and multinodular goiter. Only the surgeons had operation rates distinctly above the average $(5 \% / 8 \%): 20 \%$ of their patients with uninodular and $29 \%$ with multinodular goiter were managed surgically (Table 4).

L-Thyroxine was prescribed to $13 \% / 20 \%$ of patients with uninodular/multinodular goiter whose treatment did not involve surgery, and 24\%/28\% received preparations combining L-thyroxine and iodide. Treatment with iodide alone could not be evaluated, because iodide is available in Germany without a prescription.

To enable estimation of the number of operations for management of nodular goiter in Germany in 2006, it was first established that among the 25351 AOKinsured patients for whom partial thyroid resection (OPS 5-062)* or thyroidectomy (OPS 5-063) was documented, a total of 18785 patients $(74.1 \%$; 95\% confidence interval $[95 \% \mathrm{CI}] 73.6$ to 74.6$)$ had a diagnosis of nodular goiter. The other reasons for treatment included hyperthyroidism (ICD-10 E05; 13.3\%, 95\% CI 12.9 to 13.7 ), thyroid neoplasia (ICD-10 2006

${ }^{\star}$ The OPS (Operationen- und Prozedurenschlüssel) is the German modification of the International Classification of Procedures in Medicine codes C73 and D34); 7.8\%, 95\% CI 7.5 to 8.2), and further principal hospital diagnoses.

According to data from the German Institute for the Hospital Remuneration System (InEK), a total of 79131 thyroid gland operations were performed in Germany in 2006, 51867 of which were classified as OPS 5-062 and 27264 as 5-063 (25). Assuming the same proportion of surgery for nodular goiter in the general population as in the AOK patients, 58636 patients underwent one of the target OPS operations for nodular goiter in Germany in 2006.

\section{Discussion}

The low malignancy rate of the predominantly diagnostic thyroid nodule operations highlights the need for improvement in preoperative diagnosis and stratification of risk. Our analysis of billing data reflects the diagnosis and treatment of thyroid nodules. Compared to multinodular goiter, the results for diagnosis and treatment of uninodular goiter are affected to a much smaller extent by complaints or symptoms that could not be measured in this study. For example, while operative treatment is selected for some multinodular goiters mainly due to symptoms arising from the mass of the lesion, this is rarely the case for glands with a solitary nodule. For this reason, the discussion focuses on uninodular goiter.

In Germany, the diagnosis of uni-/multinodular goiter (Table 1) - and thus most likely also the decision of whether or not surgery is indicated - is predominantly made by primary care physicians and internists. The most prominent departure from the guideline recommendations (Figure 2) is the low rate of fine-needle cytology, 
TABLE 2a

Investigations billed in the 9-month period preceding establishment of diagnosis (averages for all specialties)

\begin{tabular}{l|c|c|c|c}
\multirow{2}{*}{ Investigation } & \multicolumn{2}{|c|}{ Uninodular goiter } & \multicolumn{2}{c}{ Multinodular goiter } \\
\cline { 2 - 5 } & $\begin{array}{c}\% \text { managed surgically } \\
(95 \% \mathrm{Cl}), \mathrm{n}=405\end{array}$ & $\begin{array}{c}\% \text { managed nonsurgically } \\
(95 \% \mathrm{Cl}), \mathrm{n}=8671\end{array}$ & $\begin{array}{c}\% \text { managed surgically } \\
(95 \% \mathrm{Cl}), \mathrm{n}=1276\end{array}$ & $\begin{array}{c}\% \text { managed nonsurgically } \\
(95 \% \mathrm{Cl}), \mathrm{n}=15248\end{array}$ \\
\hline Sonography & $100.0(99.1-100.0)$ & $85.6(84.8-86.3)$ & $84.9(82.8-86.8)$ & $74.5(73.8-75.2)$ \\
\hline Scintigraphy & $94.3(91.6-96.4)$ & $44.3(43.2-45.4)$ & $75.1(72.6-77.4)$ & $42.4(41.6-43.2)$ \\
\hline TSH & $94.6(91.9-96.6)$ & $77.6(76.7-78.5)$ & $92.1(90.5-93.5)$ & $77.3(76.6-78.0)$ \\
\hline Anti-TPO & $28.4(24.1-33.1)$ & $24.7(23.8-25.6)$ & $23.5(21.2-25.9)$ & $22.1(21.4-22.8)$ \\
\hline FNAC & $21.0(17.1-25.3)$ & $6.4(5.9-6.9)$ & $12.5(10.8-14.5)$ & $5.4(5.0-5.8)$ \\
\hline Calcitonin & $8.9(6.3-12.1)$ & $6.7(6.2-7.2)$ & $14.0(12.2-16.1)$ & $9.2(8.7-9.7)$ \\
\hline No diagnostic tests & $0.5(0.1-1.8)$ & $0.8(0.6-1.0)$ & $0.0(0.0-0.3)$ & $0.1(0.1-0.2)$ \\
\hline
\end{tabular}

95\% Cl, 95\% confidence interval; TSH, thyroid-stimulating hormone; TPO, thyroid peroxidase; FNAC, fine-needle aspiration cytology

\section{TABLE 2b}

Investigations billed in the 9-month period preceding establishment of diagnosis (by specialty)

\begin{tabular}{|c|c|c|c|c|c|c|c|c|c|c|}
\hline \multirow{3}{*}{ Investigation } & \multicolumn{5}{|c|}{ Uninodular goiter } & \multicolumn{5}{|c|}{ Multinodular goiter } \\
\hline & \multicolumn{5}{|c|}{$\begin{array}{l}\text { \% surgically managed patients / \% nonsurgically managed patients } \\
\qquad(\mathrm{n}=405)\end{array}$} & \multicolumn{5}{|c|}{$\begin{array}{l}\text { \% surgically managed patients / \% nonsurgically managed patients } \\
\qquad(\mathrm{n}=15276)\end{array}$} \\
\hline & $\begin{array}{l}\text { Internal } \\
\text { medicine }\end{array}$ & $\begin{array}{l}\text { Primary } \\
\text { care }\end{array}$ & $\begin{array}{l}\text { Nuclear } \\
\text { medicine }\end{array}$ & Surgery & Others & $\begin{array}{c}\text { Internal } \\
\text { medicine }\end{array}$ & $\begin{array}{l}\text { Primary } \\
\text { care }\end{array}$ & $\begin{array}{l}\text { Nuclear } \\
\text { medicine }\end{array}$ & Surgery & Others \\
\hline Calcitonin & $9 / 6$ & $6 / 5$ & $22 / 15$ & $6 / 5$ & $7 / 5$ & $15 / 8$ & $10 / 9$ & $28 / 26$ & $10 / 6$ & $14 / 8$ \\
\hline Anti-TPO & $18 / 13$ & $18 / 16$ & $31 / 28$ & $15 / 13$ & $18 / 15$ & $24 / 20$ & $23 / 17$ & $20 / 45$ & $11 / 15$ & $15 / 20$ \\
\hline Sonography & $100 / 85$ & $96 / 72$ & $100 / 100$ & $82 / 65$ & $100 / 94$ & $85 / 72$ & $82 / 65$ & $88 / 90$ & $78 / 72$ & $85 / 76$ \\
\hline TSH & 94 / 84 & $95 / 78$ & $100 / 96$ & $60 / 52$ & $92 / 75$ & $95 / 75$ & $85 / 74$ & $95 / 92$ & $91 / 77$ & $92 / 85$ \\
\hline FNAC & $22 / 5$ & $15 / 5$ & $42 / 12$ & $13 / 13$ & $23 / 7$ & $13 / 4$ & $12 / 5$ & $18 / 7$ & $7 / 10$ & $12 / 7$ \\
\hline Scintigraphy & $75 / 28$ & $91 / 35$ & $100 / 91$ & $83 / 39$ & $85 / 70$ & $60 / 29$ & $65 / 29$ & $95 / 87$ & $82 / 60$ & $88 / 78$ \\
\hline
\end{tabular}

TPO, thyroid peroxidase; TSH, thyroid-stimulating hormone; FNAC, fine-needle aspiration cytology

which has been in use for 50 years (24) and represents, in experienced hands, the most sensitive $(83 \%)$ and most specific (92\%) method available for diagnosis (5). FNAC was used in no more than $21 \%$ of surgically managed uninodular goiters by all specialties; nuclear medicine specialists employed it most frequently (Table $2 b$ ). Again in contrast to the prevailing guideline recommendation (25), the calcitonin level was determined in only $7 \%$ of the nonsurgically managed uninodular goiters (Table 2a). Twenty-seven to $52 \%$ of the thyroid nodules were classed as benign on sonographic criteria and could be excluded from FNAC (Figure 2) (26, 27). Furthermore, by means of FNAC ca. $70 \%$ (= benign FNAC rate [7]) of the (ca. 48 to $73 \%$ ) thyroid nodules suspected of malignancy on sonography or clinical examination could be excluded from a diagnostic operation, in the absence of other factors necessitating surgery.
The relatively uncommon preoperative use of FNAC for the diagnosis of thyroid nodule is very probably a major reason for the high number of diagnostic thyroid operations for uninodular goiter carried out in Germany with a low malignancy rate. A retrospective analysis of the thyroid carcinomas documented in the Dutch Comprehensive Cancer Registry revealed that in 33\% of the diagnosed thyroid cancers there had been no preoperative FNAC (28). Another study identified the high number of facilities with low numbers of cases (only three thyroid cancers diagnosed in 2 years/facility) as a particular reason for the low (57\%) sensitivity of FNAC across the country concerned as a whole; in contrast, high $(>95 \%)$ sensitivity of FNAC was repeatedly confirmed in centers with high numbers of cases (29).

Further studies should therefore be conducted to establish whether similar problems or budgetary reasons such 
Investigations billed in the 2-year period following establishment of diagnosis (averages for all specialties)

\begin{tabular}{l|c|c|c|c}
\multirow{2}{*}{ Investigation } & \multicolumn{2}{|c|}{ Uninodular goiter } & \multicolumn{2}{c}{ Multinodular goiter } \\
\cline { 2 - 5 } & $\begin{array}{c}\% \text { managed surgically } \\
(95 \% \mathrm{Cl}), \mathrm{n}=405\end{array}$ & $\begin{array}{c}\% \text { managed nonsurgically } \\
(95 \% \mathrm{CI}), \mathrm{n}=8671\end{array}$ & $\begin{array}{c}\% \text { managed surgically } \\
(95 \% \mathrm{Cl}), \mathrm{n}=1276\end{array}$ & $\begin{array}{c}\% \text { managed nonsurgically } \\
(95 \% \mathrm{Cl}), \mathrm{n}=15248\end{array}$ \\
\hline TSH & $81.0(76.8-84.7)$ & $48.0(46.9-49.1)$ & $26.0(23.6-28.5)$ & $34.0(33.2-34.8)$ \\
\hline Sonography & $50.1(45.1-55.1)$ & $28.0(27.1-29.0)$ & $32.0(29.4-34.6)$ & $24.0(23.3-24.7)$ \\
\hline Scintigraphy & $28.9(24.5-33.6)$ & $10.0(9.4-10.6)$ & $22.0(19.8-24.4)$ & $11.0(10.5-11.5)$ \\
\hline Calcitonin & $13.1(10.0-16.8)$ & $16.0(15.2-16.8)$ & $7.0(5.6-8.5)$ & $3.0(2.7-3.3)$ \\
\hline FNAC & $6.9(4.6-9.8)$ & $2.0(1.7-2.3)$ & $4.0(3.0-5.2)$ & $3.0(2.7-3.3)$ \\
\hline Radioiodine therapy & $0.5(0.1-1.8)$ & $0.2(0.1-0.3)$ & $0.9(0.5-1.6)$ & $0.4(0.3-0.5)$ \\
\hline
\end{tabular}

$95 \% \mathrm{Cl}, 95 \%$ confidence interval; TSH, thyroid-stimulating hormone; FNAC, fine-needle aspiration cytology

\section{TABLE 3b}

Investigations billed in the 2-year period following establishment of diagnosis (by specialty)

\begin{tabular}{|c|c|c|c|c|c|c|c|c|c|c|}
\hline \multirow{3}{*}{ Investigation } & \multicolumn{5}{|c|}{ Uninodular goiter } & \multicolumn{5}{|c|}{ Multinodular goiter } \\
\hline & \multicolumn{5}{|c|}{$\begin{array}{l}\begin{array}{l}\text { \% surgically managed patients / \% nonsurgically managed patients } \\
(\mathrm{n}=405)\end{array} \\
(\mathrm{n}=8671)\end{array}$} & \multicolumn{5}{|c|}{$\begin{array}{l}\begin{array}{l}\text { \% surgically managed patients / \% nonsurgically managed patients } \\
(\mathrm{n}=1276)\end{array} \\
(\mathrm{n}=15248)\end{array}$} \\
\hline & $\begin{array}{l}\text { Internal } \\
\text { medicine }\end{array}$ & $\begin{array}{l}\text { Primary } \\
\text { care }\end{array}$ & $\begin{array}{l}\text { Nuclear } \\
\text { medicine }\end{array}$ & Surgery & Others & $\begin{array}{l}\text { Internal } \\
\text { medicine }\end{array}$ & $\begin{array}{l}\text { Primary } \\
\text { care }\end{array}$ & $\begin{array}{l}\text { Nuclear } \\
\text { medicine }\end{array}$ & Surgery & Others \\
\hline TSH & $100 / 44$ & $100 / 45$ & $40 / 70$ & $12 / 50$ & $67 / 49$ & $26 / 35$ & $25 / 34$ & $25 / 33$ & $27 / 27$ & $24 / 32$ \\
\hline Sonography & $80 / 26$ & $65 / 26$ & $42 / 36$ & $7 / 23$ & $43 / 29$ & $33 / 23$ & $34 / 20$ & $31 / 28$ & $26 / 20$ & $28 / 22$ \\
\hline Scintigraphy & $30 / 7$ & $33 / 10$ & $23 / 15$ & $2 / 9$ & $22 / 12$ & $24 / 9$ & $20 / 9$ & $23 / 15$ & $9 / 9$ & $16 / 10$ \\
\hline Calcitonin & $13 / 13$ & $15 / 16$ & $8 / 21$ & $2 / 7$ & $9 / 13$ & $11 / 3$ & $6 / 2$ & $6 / 4$ & $4 / 2$ & $6 / 2$ \\
\hline FNAC & $9 / 2$ & $8 / 2$ & $5 / 3$ & $0 / 5$ & $7 / 2$ & $4 / 3$ & $3 / 2$ & $4 / 3$ & $2 / 1$ & $3 / 2$ \\
\hline $\begin{array}{l}\text { Radioiodine } \\
\text { therapy }\end{array}$ & $0 /<1$ & $<1 /<1$ & $<1 /<1$ & $0 / 0$ & $0 /<1$ & $<1 /<1$ & $<1 /<1$ & $<1 /<1$ & $0 / 0$ & $<1 /<1$ \\
\hline
\end{tabular}

TSH, thyroid-stimulating hormone; FNAC, fine-needle aspiration cytology

as billing limits, e.g. for sonography, low reimbursement for FNAC (130 points and 174 points respectively on the German scales for physicians' fees for treatment of patients with statutory and private health insurance, against US\$ 505 from Medicare in the USA) (30), or other factors explain the discrepancy between guideline recommendations and billed services, and perhaps also the high frequency of thyroid operations in connection with the low malignancy rate of the nodules removed.

The much more frequent use of scintigraphy in surgically than in nonsurgically treated patients with uninodular goiter (Table 2a) leads one to suspect that the decision to operate is often based more on the scintigraphy findings than on the results of sonography (for which the differences in billing frequency between surgically and nonsurgically treated patients are smaller). Although the guidelines for the diagnosis of euthyroid multinodular goiter in (previously) iodinedeficient regions recommend scintigraphy to exclude hot nodules independent of TSH measurement (5), it remains unclear why operatively treated patients with euthyroid uni-/multinodular goiter undergo scintigraphy far more often than those who do not have surgery (Table 2a). Scintigraphy is appropriate only for identification of hot spots and their exclusion from subsequent measures to diagnose malignancy, because the specificity of scintigraphy, ca. $5 \%$, is inadequate for the prediction of malignancy (31-33) and much lower than the specificity of sonography (39 to $95 \%$ for a single sonography criterion) (7). Therefore scintigraphy is not recommended for diagnosis of malignancy in the guidelines - except for the above-mentioned exclusion of hot spots $(5,9)$. Initial scintigraphy to confirm the diagnosis was followed in 2629 patients by one 
Rates of surgical management by specialty

\begin{tabular}{|c|c|c|c|c|}
\hline \multirow[t]{2}{*}{ Specialty } & \multicolumn{2}{|c|}{$\begin{array}{l}\text { Surgically managed uninodular goiter } \\
\text { ( } \% \text { of all patients in this specialty) }\end{array}$} & \multicolumn{2}{|c|}{$\begin{array}{l}\text { Surgically managed multinodular goiter } \\
\text { ( } \% \text { of all patients in this specialty) }\end{array}$} \\
\hline & $\begin{array}{c}\text { Year } 1 \\
\text { after diagnosis } \\
\mathrm{n}=325\end{array}$ & $\begin{array}{c}\text { Year } 2 \\
\text { after diagnosis } \\
\mathrm{n}=80\end{array}$ & $\begin{array}{c}\text { Year } 1 \\
\text { after diagnosis }(95 \% \mathrm{Cl}) \\
\mathrm{n}=1031\end{array}$ & $\begin{array}{c}\text { Year } 2 \\
\text { after diagnosis } \\
\mathrm{n}=245\end{array}$ \\
\hline Surgery & $16.2(8.7-26.6)$ & $4.1(0.8-11.4)$ & $24.8(18.3-32.4)$ & $3.8(1.4-8.1)$ \\
\hline Nuclear medicine & $2.9(2.0-4.1)$ & $0.8(0.3-1.5)$ & $7.1(6.2-8.1)$ & $1.6(1.1-2.1)$ \\
\hline Primary care & $3.5(2.8-4.2)$ & $0.8(0.5-1.2)$ & $6.7(6.0-7.5)$ & $1.1(0.8-1.4)$ \\
\hline Internal medicine & $3.7(3.1-4.3)$ & $0.8(0.5-1.2)$ & $5.4(4.8-6.0)$ & $1.2(0.9-1.5)$ \\
\hline Others & $3.4(2.5-4,5)$ & $1.1(0.6-1.8)$ & $5.3(4.4-6.3)$ & $2.9(2.2-3.6)$ \\
\hline Average & 3.7 & 0.8 & 6.2 & 1.5 \\
\hline
\end{tabular}

$95 \% \mathrm{Cl}, 95 \%$ confidence interval

additional scintigraphy and in 562 patients, predominantly with a nuclear medicine specialist as their treating physician, by two additional scintigraphies. This yields a repeat scintigraphy rate of $11 \%$. The reasons for repeat scintigraphy are unclear.

In the 2-year period after diagnosis, sonography was billed particularly infrequently (uninodular goiter $28 \%$, multinodular goiter $24 \%$ ) in patients whose treatment did not involve surgery (Table $3 a$ ). These low numbers may be explained by the restricted billing potential, in some of the associations of statutory health insurance physicians in Germany, for thyroid sonography as a means of monitoring the progress of thyroid nodules - despite its recommendation in the guidelines (to detect the few cases of false-negative FNAC).

Measurement of TSH to monitor the frequently required postoperative substitution therapy with thyroid hormones is billed in only $81 \%$ and $26 \%$ of surgically treated patients with uninodular and multinodular goiter respectively (Table 3a), despite being recommended in the guidelines. Particularly the latter figure is too low for timely detection and correction of hyper- or hypothyroidism (34) during substitution therapy.

The frequent treatment of uni-/multinodular goiter with thyroxine $(13 \% / 20 \%)$ is not recommended in the guidelines. Moreover, treatment of thyroid nodules with thyroxine is contraindicated in $91 \% / 75 \%$ of patients with uni-/multinodular goiter (35) and in elderly patients in general.

\section{Limitations}

The limitations of our study are, in particular, the requirement for complete documentation of billing, the possibility that inpatient diagnostic investigations were not registered, and the exclusive focus on non-hospital diagnoses. While the documentation of malignant diseases can be assumed to be reliable, this is not necessarily the case for benign illnesses.
Diagnostic investigations were recorded for a period of only 9 months before diagnosis; it cannot be ruled out that some such investigations had taken place earlier.

The frequency of therapeutic (not diagnostic) surgeries for uninodular and multinodular goiter is unknown. Equally, no statement can be made regarding the frequency of cancer in the study population. This means that the proportion of operations performed for therapeutic purposes cannot be assessed.

The billing data do not reveal whether the physicians from different specialties took care of differing collectives of patients. Therefore, interspecialty comparisons may be affected by differences among the patient groups. The data evaluated cover the period from 2005 to 2008 , and the situation may have changed in the intervening years. Furthermore, the external validity of the findings is restricted by the fact that only data from patients insured by the AOK were analyzed - although the 24971233 persons with health insurance from the AOK represent $30.4 \%$ of the German population. AOK patients are older than those not insured by the AOK, and, for instance, compared to the privately insured a higher proportion of them have chronic diseases such as diabetes and heart failure (36).

Seasonal effects cannot be ruled out when analyzing data from only one quarter of the year; however, close to a quarter $(24.8 \%)$ of the thyroid operations in 2006 were performed in the three-month period from April to June.

\section{Summary}

Our analysis of billing data shows very low frequency of use of FNAC and also of calcitonin determination in the diagnosis of both uninodular and multinodular goiter. Treatment of thyroid nodules with thyroxine continues to be common despite the absence of evidence for benefit. If FNAC were to be employed in all thyroid nodules suspected of malignancy following sonographic and clinical risk stratification, instead of in only $21 \%$ of all cases of surgically managed uninodular goiter as at present, a diagnostic thyroid operation 


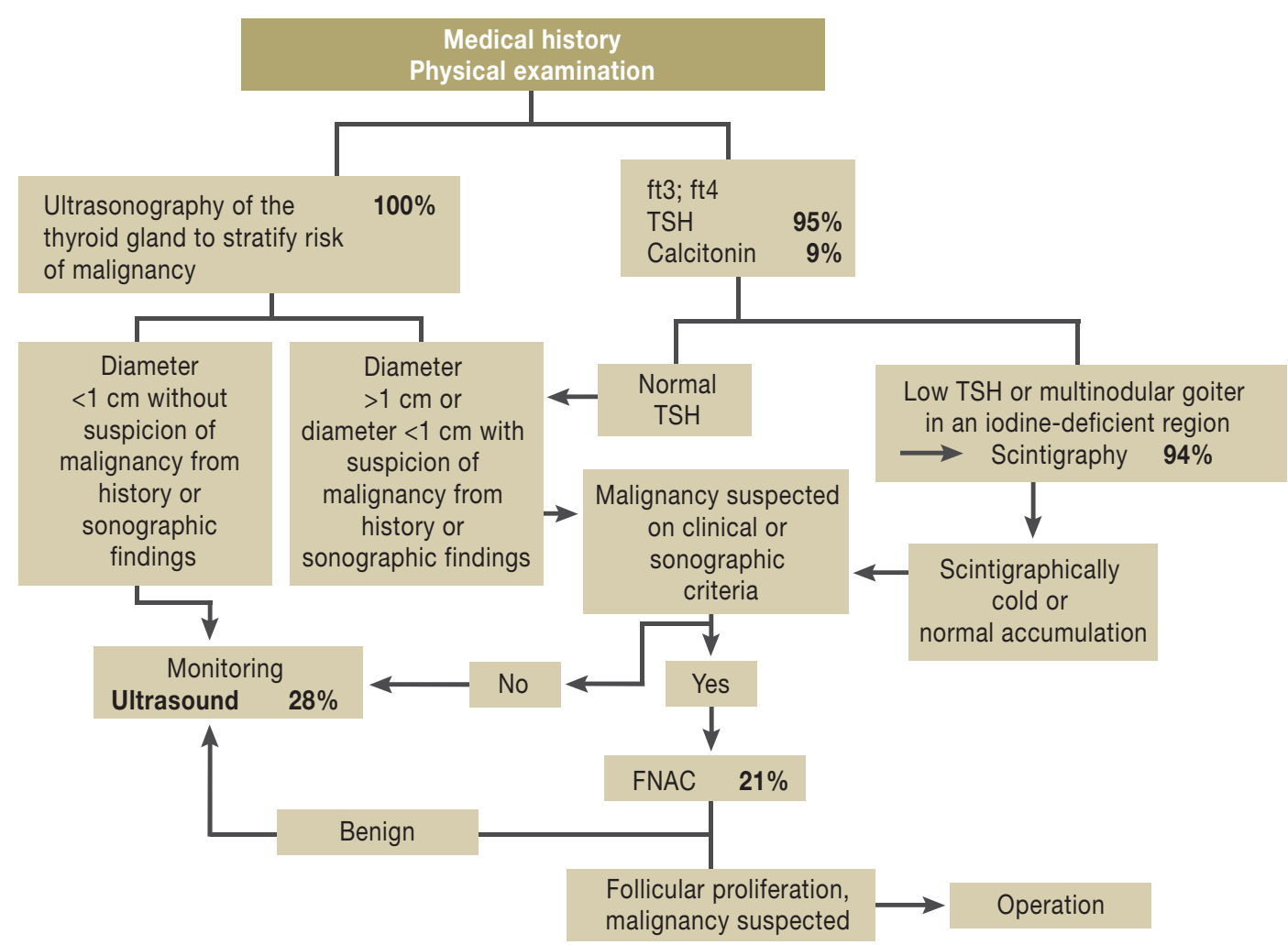

Diagnosis of thyroid nodules according to guideline ${ }^{* 1}$ and billing data ${ }^{*^{2}}$

${ }^{* 1}$ AACE/AME/ETA guidelines; a $100 \%$ target can be assumed for sonography, TSH, and calcitonin. Twenty-seven to $52 \%(26,27)$ of thyroid nodules are benign on sonographic criteria and can be excluded from FNAC. For special constellations, e.g., elevated TSH levels during investigation of a thyroid nodule or the procedure in hot nodules, see the AACE/AME/ETA guidelines.

${ }^{* 2}$ According to AOK billing data for surgically managed patients with uninodular goiter (Table 2a)

TSH, thyroid-stimulating hormone; ft3, free triiodothyronine; ft4, free tetraiodothyronine; FNAC, fine-needle aspiration cytology

could be avoided in around $70 \%$ (= benign FNAC rate [7]) of the $79 \%$ of uninodular goiters that are currently not investigated by means of FNAC, in the absence of other indications for surgery.

A single calcitonin screening leads to early diagnosis of C-cell carcinoma and thus to a better prognosis (5). For these reasons efforts should be made to improve the dissemination of the guidelines on diagnosis and treatment of thyroid nodules. Use of FNAC in all thyroid nodules suspected of malignancy on sonographic and clinical criteria, coupled with preoperative measurement of calcitonin in uni- and multinodular goiter, could greatly increase the malignancy rate in the nodules removed. Moreover, the number of diagnostic thyroid operations, with their consequences and potential complications (12-17), could be considerably reduced.

\section{Conflict of interest statement}

The authors declare that no conflict of interest exists.

Manuscript received on 5 February 2013, revised version accepted on 12 September 2013

Translated from the original German by David Roseveare.

\section{REFERENCES}

1. Volzke H, Ludemann J, Robinson DM, et al.: The prevalence of undiagnosed thyroid disorders in a previously iodine-deficient area. Thyroid 2003; 13: 803-10.

2. Robert Koch-Institut (eds.) und Gesellschaft der epidemiologischen Krebsregister in Deutschland e. V.: Krebs in Deutschland 2007/2008. $8^{\text {th }}$ edition. Berlin: Robert Koch-Institut 2012.

3. Knudsen N, Bülow I, Jørgensen T, Laurberg P, Ovesen L, Perrild H: Comparative study of thyroid function and types of thyroid dysfunction in two areas in Denmark with slightly different iodine status. Eur J Endocrinol 2000; 143: 485-91.

4. Belfiore A, La Rosa GL, Padova G, Sava L, Ippolito 0, Vigneri R: The frequency of cold thyroid nodules and thyroid malignancies in patients from an iodine-deficient area. Cancer 1987; 60: 3096-102.

5. Gharib H, Papini E, Paschke R, et al.: American Association of Clinical Endocrinologists, Italian Association of Clinical Endocrinologists and European Thyroid Association: Medical guidelines for clinical practice for the diagnosis and management of thyroid Nodules. Endocr Pract, Hot Thyroidology, J Endocrin Invest 2010; 33 Suppl 5: 1-56.

6. Cooper DS, Doherty GM, Haugen BR, Kloos, et al.: Revised American Thyroid Association management guidelines for patients with thyroid nodules and differentiated thyroid cancer. Thyroid 2009; 19: 1167-214.

7. Frates MC, Benson CB, Charboneau JW, et al.: Management of thyroid nodules detected at US: Society of Radiologists in Ultrasound consensus conference statement. Radiology 2005; 237: 794-800. 


\section{KEY MESSAGES}

- Contrary to guideline recommendations, preoperative FNAC and calcitonin determination are rarely used in the diagnostic investigation of thyroid nodules.

- This inadequate preoperative risk stratification is a possible explanation for the high number of diagnostic thyroid surgeries and the consequently low malignancy rate.

- If FNAC were used in all cases of surgically managed uninodular goiter instead of the present $21 \%$, ca. $70 \%$ of the predominantly diagnostic thyroid operations in the remaining $79 \%$ of patients with uninodular goiter could be avoided, in the absence of other indications for surgery.

- Sonography is too rarely used to monitor the disease course in thyroid nodules managed by nonsurgical means.

- There is no evidence for any benefit of thyroxine treatment for nonsurgically managed uninodular goiters, carried out in 13\% of these cases.

8. Pacini F, Schlumberger M, Dralle H, Elisei R, Smit JW, Wiersinga W: European consensus for the management of patients with differentiated thyroid carcinoma of the follicular epithelium. Eur J Endocrinol 2006; 154: 787-803

9. Paschke R, Hegedüs L, Alexander E, Valcavi R, Papini E, Gharib H: Thyroid nodule guidelines: agreement, disagreement and need for future research. Nat Rev Endocrinol 2011; 7: 354-61.

10. Li H, Robinson KA, Anton B, et al: Cost-Effectiveness of a Novel Molecular Test for Cytologically Indeterminate Thyroid Nodules. J Clin Endocrinol Metab 2011, 96: E1719-26.

11. Institut für das Entgeltsystem im Krankenhaus Anwenderhandbuch. https://daten.inek.org (last accessed July 2013)

12. Dralle $\mathrm{H}$, Sekulla C, Haerting J, et al.: Risk factors of paralysis and functional outcome after recurrent laryngeal nerve monitoring in thyroid surgery. Surgery 20041; 136: 1310-22.

13. Rosato L, Avenia N, Bernante P, et al.: Complications of thyroid surgery: analysis of a multicentric study on 14,934 patients operated on in Italy over 5 years. World J Surg 2004; 28: 271-6.

14. Scott-Combes D, Kinsman R: The British Association of Endocrine Surgeons second national audit Report 2007. Dendrite clinical systems. Oxfordshire, United Kingdom: Dendrite Clinical Systems Ltd 2007.

15. Bergenfelz A, Jansson S, Kristoffersson A, et al.: Complications to thyroid surgery: results as reported in a database from a multicenter audit comprising 3,660 patients. Langenbecks Arch Surg 2008; 393: $667-73$.

16. Bennedbaek FN, Perrild H, Hegedüs L: Diagnosis and treatment of the solitary thyroid nodule. Results of a European survey. Clin Endocrinol 1999; 50: 357-63.

17. Dietlein M, Wegscheider K, Vaupel R, Schmidt M, Schicha H: [Survey of management of solitary thyroid nodules in Germany]. Nuklearmedizin 2008; 47: 87-96

18. Führer D, Mügge C, Paschke R.: Questionnaire on management of nodular thyroid disease (Annual Meeting of the Thyroid Section of the German Society of Endocrinology 2003). Exp Clin Endocrinol Diabetes 2005; 113:152-9.

19. Franklyn JA: Lack of consensus in Europe in the management of nontoxic multinodular goitre. Clin Endocrinol 2000; 53: 3-4.
20. Mangiapane S, Busse R: Prescription prevalence and continuing medication use for secondary prevention after myocardial infarction: the reality of care revealed by claims data analysis. Dtsch Arztebl Int 2011; 108(50): 856-62.

21. Borden WB, Redberg RF, Mushlin Al, Dai D, Kaltenbach LA, Spertus JA: Patterns and intensity of medical therapy in patients undergoing percutaneous coronary intervention. JAMA 2011; 305: 1882-9.

22. Schubert I, Hein R, Abbas S, Thürmann P: The frequency of prescription of immediate-release nifedipine for elderly patients in Germany: utilization analysis of a substance on the PRISCUS list of potentially inappropriate medications. Dtsch Arztebl Int 2012; 109(12): 215-9.

23. Hauner $\mathrm{H}$, Köster I, Schubert I: Trends in der Prävalenz und ambulanten Versorgung von Menschen mit Diabetes mellitus. Eine Analyse der Versichertenstichprobe AOK Hessen/KV Hessen im Zeitraum von 1998 bis 2004. Dtsch Arztebl 2007; 104(41): A 2799-805.

24. Martin H, Ellis EB: Biopsy by nedle puncture and aspiration. Ann Surg 1930; 92: 169-81.

25. Dietlein M, Dressler J, Joseph K, Leisner, et al.: Guidelines in thyroid diagnosis. Nuklearmedizin 1999; 38: 215-8.

26. Russ B, Royer B, Bigorgne C, et al.: Prospective evaluation of thyroidimaging reporting and data system on 4550 nodules with and without elastography. Eur J Endocrinol 2013; 168: 649-55.

27. Horvath E, Malilis S, Rossi R, et al.: An ultrasonogram reporting system for thyroid nodules stratifying cancer risk for clinical management. $J$ Clin Endocrinol Metab 2009; 90: 1748-51.

28. Giard RW, Hermans J: Use and accuracy of fine-needle aspiration cytology in histologically proven thyroid carcinoma: an audit using a national nathology database. Cancer 2000; 90(6): 330-4.

29. Ravetto C, Colombo L, Dottorini ME: Usefulness of fine-needle aspiration in the diagnosis of thyroid carcinoma: a retrospective study in 37,895 patients. Cancer 2000; 90: 357-63.

30. Yip L, Farris C, Kabaker AS, et al.: Cost impact of molecular testing for indeterminate thyroid nodule fine-needle aspiration biopsies. J Clin Endocrinol Metab 2012, 97: 1905-12.

31. Ashcraft MW, van Herle AJ: Management of thyroid nodules. II: Scanning techniques, thyroid suppressive therapy, and fine needle aspiration. Head Neck Surg 1981; 3: 297-322.

32. Kneafsey B, Gillen P, Brady MP: Limitations of thyroid scanning in solitary thyroid nodules. Ir J Med Sci 1994; 163: 451-4.

33. Paschke R: Ein Meer von Schilddrüsenknoten - Wann muss punktiert werden. MMW 2010; 13: 41-4.

34. Canaris GS, Manowitz NR, Mayour G, Ridgway EC: The Colorado thyroid disease prevalence study. Arch Int Med 2000; 160: 526-34.

35. Fast S, Bonnema SJ, Hegedüs L: The majority of Danish nontoxic goitre patients are ineligible for Levothyroxine suppressive therapy. Clin Endocrinol (0xt) 2008t; 69: 653-8.

36. Hoffmann F, Icks A: Unterschiede in der Versichertenstruktur von Krankenkassen und deren Auswirkungen für die Versorgungsforschung: Ergebnisse des Bertelsmann-Gesundheitsmonitors. Gesundheitswesen 2012; 74: 291-7.

\section{Corresponding author}

Prof. Dr. med. Ralf Paschke

Klinik für Endokrinologie und Nephrologie

Universität Leipzig

Liebigstr. 20, 04103 Leipzig, Germany

Ralf.Paschke@medizin.uni-leipzig.de

eBox:

www.aerzteblatt-international.de/13m0827 


\title{
The Management of Thyroid Nodules
}

\author{
A Retrospective Analysis of Health Insurance Data
}

Romy Wienhold, Markus Scholz, Jürgen-Bernhard Adler, Christian Günster, Ralf Paschke

\section{Description of method}

The analysis was based on anonymized routine data collected nationwide by the AOK. The evaluated billing data covered outpatient medical services according to $\S 295$ of the German Social Code V (SGB V) and prescriptions according to $\S 300$ SGB V, as well as inpatient services according to $\S 301$ SGB V, which contain information on diseases, interventions, lengths of stay, transfers, and reasons for discharge. Anonymized basic data such as the patient's age, sex, and insurance status were included in the analysis. On this basis, various hospital stays and physician visits could be assigned to one and the same patient by means of an identification number without permitting reidentification of the person concerned. Data from the years 2005 to 2008 were used.

On the reference date of 1 July 2006, the AOK provided health insurance for 24971233 persons. Analysis of care provision and prescription data identified 25600 patients insured by the AOK who were treated on an outpatient basis and in whom a first confirmed diagnosis of uni- or multinodular goiter was made in the second quarter of 2006 (with no diagnosis during the previous 12 months).

A total of 9076 patients were assigned to ICD-10 code E04.1: "Nontoxic single thyroid nodule." We refer to these thyroid glands as "uninodular."

The remaining 16524 patients were assigned to ICD code E04.2: "nontoxic multinodular goiter (cystic goiter NOS [not otherwise specified], multinodular [cystic] goiter NOS)" or E01.1: "lodine deficiency-related multinodular (endemic) goiter." We refer to these thyroid glands as "multinodular."

For both uni- and multinodular patients, we evaluated all diagnostic services billed to the AOK during the 9 months immediately preceding the second quarter of 2006 and all subsequent examinations and treatments (including surgical interventions and radioiodine therapy) billed during a period of 2 years directly following the second quarter of 2006. The patient selection procedure is depicted in Figure 1. The statistical software SPSS was used for data analysis. The data were evaluated by specialty of physician (internal medicine, primary care, nuclear medicine, surgery). All other specialties were grouped together as "other". Each patient was assigned to the specialty of the physician who was the first to make a thyroid-relevant diagnosis in the second quarter of 2006. All cases in which the above-mentioned diagnoses were made by physicians from two or more specialties within the second quarter of 2006 (2.8\%) were excluded. In both the uninodular and the multinodular group, patients who underwent surgery (405/1276) were evaluated separately from those who did not (8671/15 248). "Surgery" here means that the patient received one of the abovementioned diagnoses in the second quarter of 2006 and underwent a thyroid operation in the 2-year period directly thereafter. "Thyroid operations" were all surgical interventions assigned the following OPS codes from the 2006 catalog (target OPS): 5-062.1 "Excision of a thyroid nodule;" 5-062.4 "Unilateral subtotal resection with excision of a contralateral node;" 5-062.5 "Unilateral subtotal resection with contralateral hemithyroidectomy;" 5-062.7 "Resection of the isthmus;" 5-062.8 "Subtotal resection;" 5-063.0 "Thyroidectomy without parathyroidectomy;" 5-063.2 "Thyroidectomy with parathyroidectomy" (OPS = Operationen- und Prozedurenschlüssel, the German modification of the International Classification of Procedures in Medicine).

The percentages in Tables $2 a, b$ and $3 a, b$ refer to the numbers of patients for whom the given examination was billed expressed as a proportion of the patients in the subgroup concerned (uninodular/multinodular, surgery/no surgery) originally diagnosed by the given group of physicians.

The prescription data and the Anatomical Therapeutic Chemical (ATC) Classification System for 2006 were used to identify prescriptions of L-thyroxine (H03AA01) and preparations combining L-thyroxine and iodide (H03AA51) in the 2 years immediately following the second quarter of 2006. An average daily defined dose (DDD) of " $\mu$ g" was defined as "No drug treatment." All DDDs between " $0.1 \mu g$ " and " $150 \mu \mathrm{\mu g}$ " were defined as "Drug treatment received."

Finally, all thyroid operations in AOK patients in the whole of the year 2006 were analyzed to determine the proportion made up by goiter patients with the target operations, permitting an estimate of the annual number of goiter-related thyroid operations in Germany. 